\title{
Insecticide-impregnated netting as a potential surface treatment: an alternative to insecticide spraying for control of the leishmaniasis vector Lutzomyia longipalpis (Diptera: Psychodidae)?
}

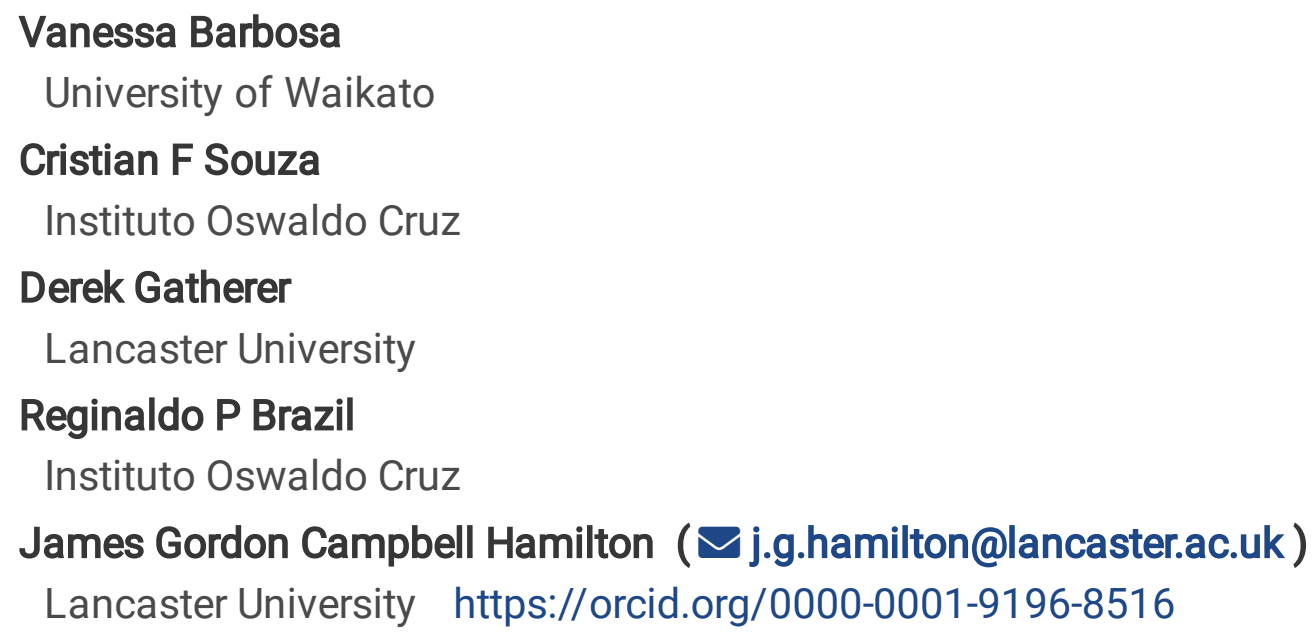

\section{Research}

Keywords: Insecticide-impregnated netting, residual insecticide spray, vector control, Lutzomyia longipalpis, Leishmania infantum, sex-aggregation pheromone, Olyset Plus, Interceptor, \-cyhalothrin, \cypermethrin

Posted Date: August 4th, 2020

DOI: https://doi.org/10.21203/rs.3.rs-52839/v1

License: (c) (i) This work is licensed under a Creative Commons Attribution 4.0 International License. Read Full License 


\section{Abstract}

Background: The sand fly, Lutzomyia longipalpis, is the main vector of Leishmania infantum in Brazil. A previous laboratory study showed that covering surfaces with insecticide-impregnated netting may provide an alternative method for killing sand flies. Synthetic male Lu. longipalpis sex/aggregation pheromone co-located with micro-encapsulated l-cyhalothrin demonstrated the potential of "lure-and-kill" to significantly reduce canine infection and sand fly densities. In this study we were interested to determine if insecticide impregnated netting could replace sprayed insecticide for Lu. longipalpis control.

Methods: We placed synthetic pheromone in experimental and real chicken sheds treated with a $1 \mathrm{~m}^{2}$ surface of either sprayed insecticide or insecticide-impregnated netting. Two experiments in experimental chicken sheds were carried out to determine the effect of the insecticide treatments on Lu. longipalpis over 1-week and 16-week periods. We counted the number of Lu. longipalpis collected overnight and dead at 24 hours. Two longitudinal intervention studies were carried in real chicken sheds and compared the numbers of Lu. longipalpis (collected and dead at $24 \mathrm{~h}$ ) before adding the intervention (either the netting or sprayed insecticide treatments) with the numbers collected $24 \mathrm{~h}$ after the intervention.

Results: In the first experiment all flies caught in the spray treated experimental chicken sheds were dead at 24 hours and in netting treated sheds $97 \%$ of females and $88 \%$ of males were dead at 24 hours ( 257 vs 225 , Wilcoxon Signed Ranks Test $P=0.043$ ). The netting and spray treated traps were equally effective at killing both female and male Lu. longipalpis over the first 8-weeks however after 16-weeks both treatments killed a significantly lower proportion of females ( $64 \% \mathrm{vs} 96 \% ; P=0.000)$ and males $89 \% \mathrm{vs}$ $100 \% ; P=0.000$ ) compared to the beginning. In the first of the longitudinal studies in real chicken sheds only the netting intervention significantly increased the proportion of females dead after $24 \mathrm{~h}(60 \% \mathrm{vs} 81 \%$; $P=0.042$ ). The subsequent study showed that both netting and spraying treatments had similarly significant impacts on the proportion of females dead after 24h (netting: $60 \% \mathrm{vs} 80 \%: P=0.0194$ and spraying: $43 \%$ vs $72 \%$ : $P=0.0004$ ).

Conclusions: The netting and spray insecticide interventions (with synthetic sex/aggregation pheromone) have similar impacts on the Lu. longipalpis population.

\section{Background}

Visceral leishmaniasis (VL) is an important neglected tropical disease around the world, with over 350 million people at risk of infection and an estimated 50,000 deaths per year[1]. Brazil is one of six countries that have $90 \%$ of all reported VL cases and the disease, caused by the Protist parasite Leishmania (Leishmania) infantum (Kinetoplastida: Trypanosomatidae), is transmitted by the sand fly Lutzomyia longipalpis (Diptera: Psychodidae) from infected domestic dogs, Canis familiaris (Carnivora: Canidae) the reservoir host, to humans[1, 2].

Despite the vector control strategies adopted by the Brazilian Ministry of Health $(\mathrm{MoH})$ over the past 20 years, the geographical range of $\mathrm{Lu}$. longipalpis is spreading $[3,4]$. The $\mathrm{MoH}$ sand fly control programme 
is reactive and on the diagnosis of a human case, the home of the infected person, and any other human or animal dwelling within a $200 \mathrm{~m}$ radius, is sprayed with a residual insecticide[5]. In addition, the $\mathrm{MoH}$ proactively monitor dog infection and when an infected dog is identified, it is euthanised[6]. These vector and infection control strategies have not reduced the incidence of the disease in dogs or humans[7-11] and a recent analysis has shown that the burden of disease caused by VL more than doubled between 1990 and 2016[12].

Spraying insecticide for sand fly control is challenging for local health authorities because of the cost and effectiveness of the activity. In Brazil, the $\mathrm{MoH}$ recommend that after the initial insecticide treatment it must be repeated after three to four months[5]. In addition, to ensure effectiveness of insecticide application and to avoid the development of resistance in the vector, residual insecticide spraying requires trained people with appropriate infrastructure to ensure well-maintained spraying equipment and an effective application regime[13, 14].

In the peridomestic environment large aggregations of male and female Lu. longipalpis become established on or near host animals[15]. These heterogeneously distributed aggregations are where the females take a blood meal and mate. Although it is not clear why some aggregation sites are favoured over other potential sites, the aggregation behaviour is largely driven by the male produced sexaggregation pheromone[16, 17]. The use of insecticide has a disruptive effect on Lu. longipalpis aggregation formation and those males that arrive first at an insecticide treated site are killed and therefore further recruitment of females and males is stopped[18]. A consequence of this disruption is that new sand fly aggregations may occur at sites that have not been treated with insecticide[18, 19]. In practice, this means that most of the insecticide used is wasted as a long-term Lu. longipalpis vector control tool[18]. The use of synthetic sex/aggregation pheromone in insecticide treated sites overcomes the disruptive effect of the insecticide by continuing to attract female and male sand flies $[19,20]$ and a controlled release formulation of the pheromone can attract $L u$. longipalpis for up to 12 weeks[21] greatly extending the lethal effect of the insecticide[22, 23]. A trial of the synthetic sex/aggregation, $(S)-9$ methylgermacrene-B[24], formulated in a long-lasting controlled release device[20, 21] co-located with microencapsulated I-cyhalothrin in chicken roosting sites significantly reduced Lu. longipalpis densities, canine Leishmania parasite infection incidence, tissue loads and canine seroconversion incidence establishing the potential for this strategy to reduce disease incidence[25].

A previous laboratory study found that Blue Olyset netting (Sumitomo Chemical Co. Ltd., Tokyo, Japan), impregnated with $2 \%$ permethrin, was an effective replacement for sprayed microencapsulated Icyhalothrin (20 mg a.i.m ${ }^{-2}$ ) (Demand CSW; BASF PLC, Cheshire, UK)[26]. That study proposed that as insecticide impregnated netting can remain active for several years and is widely available as the main intervention against malaria transmission and thus readily available, its use in Lu. longipalpis control could overcome some of the challenges of residual insecticide spraying (staff training, dose control, cost, efficacy, incidental environmental contamination and support infrastructure)[27]. 
The aim of these experiments was to determine if application of insecticide impregnated netting under field conditions could be an effective replacement for residual insecticide spraying for Lu. longipalpis control. Thus, we compared the lethal effect of a-cypermethrin impregnated netting (Interceptorò , BASF Chemical Co.) with I-cyhalothrin residual spray in experimental chicken sheds and permethrin $(2 \%)+$ piperonyl butoxide (1\%) impregnated netting (Olyset Plus ${ }^{\circ}$, Sumitomo Chemical UK PLC) with acypermethrin residual insecticide spray in real chicken sheds.

Both residual spay insecticides are currently recommended by the Brazilian MoH for Leishmania vector control, Interceptor ${ }^{\grave{O}}$ netting is currently used for malaria vector control in endemic parts of Brazil and Olyset Plus ${ }^{\grave{D}}$ is currently used for malaria vector control in endemic parts of Africa.

The netting and spray treatments used in the experimental chicken sheds were different to those used in the real chicken shed experiments because we were only able to use those insecticide treatments (spray and net) that were available to the project at the time. The objective of the experiments was to compare the effect of spray insecticide treatments with netting insecticide treatments and not to compare the efficacy of the different insecticides.

\section{Methods}

\section{Study site}

The study took place in Governador Valadares (GV), a municipality of approximately 280,000 people in

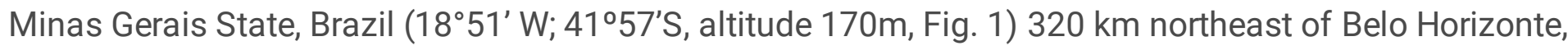
the state capital. This area is a focus of intense VL transmission and is also endemic for cutaneous leishmaniasis where the sand fly vector, Lu. longipalpis is abundant[28, 29]. GV is situated in the Rio Doce basin within the Atlantic Forest region and local topography consists of valleys and hills. The climate is the Aw type (tropical sub-warm and sub-dry) according to the Köppen-Geiger classification[30]. GV has an average temperature of $24.2^{\circ} \mathrm{C}$, ranging from 15.2 to $33^{\circ} \mathrm{C}$, and the average annual rainfall is $1109 \mathrm{~mm}$ concentrated between October and March[31].

Fig. 1 Location of trapping sites for the experiments in the municipality of Governador Valadares, Brazil.

\section{Insert Figure 1}

Experiments were carried out in the private gardens and yards of volunteer householders. The dates of trapping and location of the sites are summarised in Additional file 1. Typically, the householder's gardens consisted of a walled-in area at the front or back of the property which contained fruit trees, other types of shrubs and mature trees and animal shelters. Experiments 1 and 2 were carried out in experimental chicken sheds (2015) in the Vila Parque Ibituruna neighbourhood and experiments 3 and 4 were carried out in the householder's own chicken sheds (2019) in the Vila Isa and Vilage da Serra, neighbourhoods. These neighbourhoods are typical peri-urban areas, with homes built near the Área de Preservação Ambiental (APA) Ibituruna forest reserve. 
The inclusion criteria for all experiments were that the households had a yard containing a chicken shed with chickens and that $L u$. longipalpis were present. Presence of $L u$. longipalpis was confirmed through preliminary sampling in the householder's chicken shed. Solvent (hexane) extracts of individual sand flies collected in GV both prior to and during field experiments were examined by coupled gas chromatography-mass spectrometry (GC/MS) [32] to confirm that they produced (S)-9-methylgermacreneB sex/aggregation pheromone.

Taxonomic identification of sand fly species and their sex (male or female) for all experiments was by microscope (Nikon SMZ 445) examination of morphological characteristics. Male Lu. longipalpis were initially identified by the presence of a pale spot on abdominal tergite IV and then confirmed by the morphological characteristics of the genitalia[33,34]. Females were dissected and the cibarium and spermathecae examined to confirm species identification[34].

\section{Chicken sheds}

Experimental chicken sheds used in experiments 1 and 2, were constructed from 4 plywood panels each measuring $105 \mathrm{~cm}$ high x $55 \mathrm{~cm}$ wide arranged in a square plan $(55 \mathrm{~cm} \times 55 \mathrm{~cm})$. The panels were held together by plastic cable-ties passed through holes $(10 \mathrm{~mm}$ diameter) in the top and bottom corners of each panel. Sand flies were collected in miniature suction traps manufactured in Brazil (Hoover Pugedo (HP))[35]. The light bulb was removed from the trap and instead a pheromone lure, containing $10 \mathrm{mg}$ of synthetic sex pheromone (( \pm -9-9-methylgermacrene-B), was attached to the underside of the lid of each trap[21]. The trap was suspended inside the experimental chicken shed from a wooden dowel $(20 \mathrm{~mm}$ diameter) placed across the top of the shed. Sand flies were collected in a nylon Barraud cage $(22 \mathrm{~cm} x$ $22 \mathrm{~cm} \times 22 \mathrm{~cm}$ ) suspended below the HP trap. A chicken, supplied with food and water, from the household flock was placed on the ground inside the experimental chicken shed overnight.

The chicken sheds used in experiments 3 and 4 belonged to the householders and were constructed primarily out of locally available recycled wood but also included corrugated metal, asbestos sheet and plastic. Their primary function was to shelter the chickens from nocturnal predators and thus they have walls, a roof and a door. Once closed after dusk the chickens remained in the shed throughout the night until they were released by the householder in the morning. The sheds used in the study were selected on the basis of their size (range 1 to $10 \mathrm{~m}^{2}$ ) and the number of chickens that they contained (5 to 30 ).

\section{Insecticide treatment}

For experiments 1 and 2 a single layer of netting (Interceptor ${ }^{\circledR}$, BASF S.A., São Paulo, Brazil) impregnated with a-cypermethrin $\left(6.7 \mathrm{~g} / \mathrm{kg}\right.$ or $\left.200 \mathrm{mg} / \mathrm{m}^{2}\right)$ was fixed onto plywood panels $(0.5 \mathrm{~m} \times 0.5 \mathrm{~m})$ and four of these were fitted on the inside at the top of the 4 interior walls of the experimental chicken shed. The total area covered was $1 \mathrm{~m}^{2}$. In addition 4 plywood panels $(0.5 \mathrm{~m} \times 0.5 \mathrm{~m})$ were sprayed with microencapsulated I-cyhalothrin (Karate Zeon 50 CS, Syngenta, Huddersfield, UK; $20 \mathrm{mg}$ a.i. $\mathrm{m}^{-2}$ ) which were then fitted inside 
at the tops of the 4 walls of the experimental chicken shed. The total area treated was $1 \mathrm{~m}^{2}$ and the insecticide was applied at the dosage required by the Brazilian MoH VL control handbook[5].

For experiments 3 and 4 a single layer of Olyset ${ }^{\circledR}$ Plus netting (Sumitomo Chemical Company UK PLC, London, UK) polyethylene netting impregnated with permethrin $\left[2.0 \% \mathrm{w} / \mathrm{w}\left(20 \mathrm{~g} \mathrm{~kg}^{-1} \pm 5 \mathrm{~g} \mathrm{~kg}^{-1}\right)\right.$ about $800 \mathrm{mg}$ of permethrin $\left./ \mathrm{m}^{2}\right]$ combined with piperonyl butoxide (PBO) as a pyrethroid synergist $[1.0 \% \mathrm{w} / \mathrm{w}$ $\left(10 \mathrm{~g} \mathrm{~kg}^{-1} \pm 2.5 \mathrm{~g} \mathrm{~kg}^{-1}\right)$ about $400 \mathrm{mg}$ of PBO m $\left.\mathrm{m}^{-2}\right]$ was fixed onto a plywood panel $(1 \mathrm{~m} \times 1 \mathrm{~m})$ and placed inside the real chicken shed. A plywood panel $(1 \mathrm{~m} \times 1 \mathrm{~m})$ sprayed with a-cypermethrin (Alfatek $200 \mathrm{SC}$, Rogama) $\left(20 \mathrm{mg} \mathrm{m}^{-2}\right)[5]$ was placed inside the chicken shed.

\section{Experimental design}

\section{Experiment 1}

To compare the lethal effect of insecticide-treated netting with the lethal effect of insecticide spraying over a 24-hour period we conducted an experiment over 4 nights at the 2 houses A and B (Fig. 1). Two pairs of traps were used at each house and the position of the traps within a pair was swapped on the second night to control for any positional bias (1 replicate). The trapping cycle was repeated on subsequent nights. The experimental design gave a total of 32 possible trap catch data points from 8 replicates. Replicates were excluded from the analysis unless a complete set of data was obtained for the replicate (for example if one or more of the traps did not function correctly on any pair of nights) thus we obtained 28 trap-catch data points from 7 experimental replicates.

Experimental chicken sheds were placed in the residential gardens of each of the two houses ( $A$ and $B$ ) prior to sunset (approximately 18:00). The experimental chicken sheds in each pair were $3 \mathrm{~m}$ apart and the 2 pairs in each household were $5 \mathrm{~m}$ from each other. The two households were $25 \mathrm{~m}$ apart. Each pair of experimental chicken sheds consisted of one fitted with sprayed insecticide treated wooden panels and the other one fitted with insecticide impregnated netting treated wooden panels.

The following morning (approximately $14 \mathrm{~h}$ after the traps were placed) the HP traps and attached Barraud cages were removed and the chickens released. The number of live and dead female and male Lu. longipalpis sand flies in each Barraud cage were then counted.

The live sand flies were transferred to plastic holding pots $(9.5 \mathrm{~cm}$ diam, $8 \mathrm{~cm}$ deep) with a nylon netting top. The base of the holding pot was filled with Plaster of Paris $(0.5 \mathrm{~cm}$ deep) dampened to maintain humidity. A piece of cotton wool, soaked in a solution of $20 \%$ sucrose and $50 \%$ honey syrup, was placed on the top of each holding pot as a sugar source for the sand flies. The pots were placed on a layer of moistened filter paper in the bottom of a Styrofoam box $(28 \mathrm{~cm} \mathrm{~L} \times 24 \mathrm{~cm} \mathrm{~W} \times 35 \mathrm{~cm} \mathrm{D})$ and covered with a dark cloth and kept for an additional $10 \mathrm{~h}$ after which the number of live and dead, male and female sand flies in each pot were counted again. 
Thus, we noted the total number of male and female sand flies collected as well as the total number of males and females that were dead $24 \mathrm{~h}$ after the traps were placed.

\section{Experiment 2}

To compare the lethal effect of insecticide treated netting with residual spraying over an extended period of time (16-weeks) two pairs of traps were again placed at each of the 2 houses used in experiment 1 and trapping was performed over 4 nights at each of 3 timepoints; week 1 (in May), week 8 (in July) and week 16 (in September). In total 8 replicates for each time point, were attempted. However, as before, replicates were excluded from the analysis if they were partially completed. Thus, we had 6 replicates at $T=0,7$ replicates at $\mathrm{T}=8$ weeks and 8 replicates at $\mathrm{T}=16$ weeks (total $=21$ replicates $=84$ data points).

When not in use the insecticide treated panels were removed from the experimental chicken sheds and kept uncovered and thus exposed to the prevailing weather conditions.

\section{Experiments 3 and 4}

To compare the effect of sprayed insecticide with netting insecticide treatments on Lu. longipalpis in real chicken sheds two longitudinal intervention studies[19] were carried out during an 2-week period from 06/05/2019-17/05/2019 (experiment 3) and a 5-week period from 27/08/2019-24/09/2019 (experiment 4). The distances between experimental sites varied from 82 metres (between house 1 and 2), to 3,110 metres (between house 1 and 6). In experiment 3 seven chicken sheds and 6 replicates were used for each insecticide treatment; spray or netting. In experiment 4 the number of chicken sheds was reduced to 4 and the number of replicates increased to 10 to reduce variability.

On the first night of the experiment an HP trap (without a light) and a pheromone lure (ca. $30 \mathrm{~cm}$ from the trap) was placed inside each of the chicken sheds at $6 \mathrm{pm}$. The trap and pheromone remained in position in the chicken shed overnight. The next morning, approximately 12 hours later, the cages containing the sand flies collected overnight were removed and the number of sand flies (male and female, dead and alive) was recorded. Live sand flies were removed from the collection cage and placed in a pot and held for a further 12 hours. On the evening after the first night of trapping a $1 \mathrm{~m}^{2}(1 \times 1 \mathrm{~m})$ insecticide treated wooden board (treated with either Olyset Plus netting or a-cypermethrin spray) was added to the chicken shed about $30 \mathrm{~cm}$ from the HP trap and pheromone. A fresh collection cage was attached to the HP trap.

The next morning the overnight sand fly collection was removed, and sand flies processed as before. The insecticide treatment, pheromone lure and HP trap were also removed from the chicken shed.

Thus at the end of the period, we noted the total number of male and female sand flies collected as well as the total number of males and females that were dead after $24 \mathrm{~h}$ both before and after the application of the intervention.

Chickens were present throughout each experiment (average \pm sem $=14.6 \pm 3.3$ per shed for experiment 3 and 20.0 \pm 3.7 per shed for experiment 4). 
During the experiment the chicken sheds were visited twice with an interval of 7 days between the first visit and the second visit.

\section{Control Data}

To obtain control data on the lethal effect of capturing, transferring and holding Lu. longipalpis in a plastic pot, we placed an HP trap, with a tungsten light only, beside the real chicken shed of each of the 2 study houses. The sand flies that were collected were counted and placed in holding pots in the same way as the Lu. longipalpis exposed to the different insecticide treatments. Their mortality was recorded at the same time intervals as for the experiments described above. To avoid causing mortality through handling species identity was determined at the end of the experiment.

\section{Data analysis}

\section{Experiment 1}

Prior to analysis data were checked for normality by Shapiro-Wilk and Kolmogorov-Smirnov tests. Comparisons between the numbers of sand flies (male and female) caught in experimental chicken sheds treated with insecticide impregnated netting and the numbers caught in the chicken sheds sprayed with residual insecticide was made by Wilcoxon signed-rank test. The numbers of males and females dead $24 \mathrm{~h}$ after exposure to the 2 treatments was compared by Wilcoxon signed-rank test. Differences in numbers due to night of testing and location of testing were assessed using a Kruskal-Wallis test.

\section{Experiment 2}

The data were tested for normality using both Kolmogorov-Smirnov and Shapiro-Wilk tests. Comparisons of sprayed insecticide and netting insecticide treatments on the numbers of sand flies (total, male and female) caught in each treatment and their mortality after $24 \mathrm{~h}$ were made. Numbers trapped and dead after $24 \mathrm{~h}$ were compared using the Wilcoxon signed-rank test. The effect of time (month when the experiment was performed) on the effectiveness of either netting or spray insecticide treatment was investigated with a Kruskal-Wallis test (non-parametric equivalent of a 1-way ANOVA). The effect of any interaction between the treatment and month was also investigated using a Kruskal Wallis test.

\section{Experiment 3}

As the data set for experiment 3 was small, a non-normal distribution was assumed. Comparisons of sprayed insecticide and netting insecticide treatments on the numbers of sand flies (total, male and female) caught in each treatment and their mortality after $24 \mathrm{~h}$ were made. Numbers trapped and dead after $24 \mathrm{~h}$ were compared using the Wilcoxon signed-rank test. Comparison of the proportions of $L u$. longipalpis collected and dead at $24 \mathrm{~h}$ were made by Fishers exact test.

\section{Experiment 4}


The data obtained in experiment 4 was tested for normality and subsequently analysed by nonparametric Mann-Whitney test to compare the absolute numbers of male and female Lu. longipalpis trapped and dead after $24 \mathrm{~h}$ in the sprayed and netting treated real chicken sheds. Comparison of the proportions of $L u$. longipalpis collected and dead at $24 \mathrm{~h}$ were made by Fishers exact test.

\section{Control traps}

The numbers of sand flies that were trapped in each of the 4 months (Jan, May, July and Sept) in the absence of insecticide treatment were tested for normality using Shapiro-Wilk and Kolmogorov-Smirnov tests. Sex differences in the numbers caught and dead at 24h were compared using Wilcoxon's signedrank test. Differences in numbers between houses were also tested using Wilcoxon's signed-rank test. Differences in numbers between months were tested using a Kruskal-Wallis test.

\section{Results}

\section{Experiment 1}

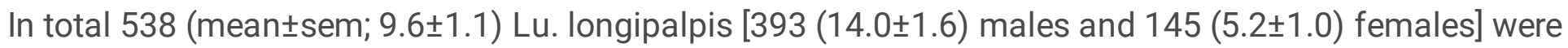
collected in 14 nights of trapping in both spray and netting treated experimental chicken sheds (Table 1). The overall ratio of males:females was 2.7:1.

\section{Insert Table 1}

Trapping data for night 1 (N1) house A1 and night 2 (N2) house A1 was not included because the CDC trap failed on N1. More male flies were caught than female flies, across all traps and locations (393 vs 145; Mann-Whitney U-test $P=0.001$ ).

More male flies were caught in netting treated sheds than in spray treated sheds ( 257 vs 136, Wilcoxon signed-rank test, $P=0.018$ ) however, the numbers of females caught in net treated sheds compared to spray treated sheds (87 vs 58 ) was not statistically significant $(P=0.410)$.

All flies caught in the spray treated sheds were dead at 24 hours. However, in the netting treated sheds $97 \%$ of females ( 87 vs 84 , ns) and $88 \%$ of males ( 257 vs 225 , Wilcoxon Signed Ranks Test $P=0.043$ ) were dead at 24 hours. Overall the night of testing (Kruskal-Wallis test $P=0.148$ ) and the location of the traps (Kruskal-Wallis test $P=0.251$ ) had no significant effect on the outcomes.

The results of this experiment suggest that spraying and netting treatments were equally effective at killing females although spraying may be more efficient at killing males than netting. However, as a significantly greater number of males were caught in netting treated sheds ( 257 vs 136 , Wilcoxon signedrank test $P<0.018)$ the netting treated sheds therefore produced the greatest male mortality (225 vs 136 , Wilcoxon signed-rank test $P<0.028$ ).

\section{Experiment 2}




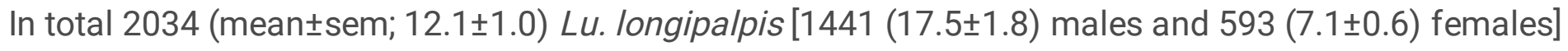
were collected during 42 nights in three 1-week trapping periods in May, July and Sept 2015 (summary data Table 2 and full data Additional file 2). The overall ratio of males:females was 2.4:1 and significantly more males than females were caught in both the net and spray treated experimental chicken sheds (Wilcoxon signed-rank test, $P<0.001$, for both).

\section{Insert Table 2}

Neither netting or spray treated experimental chicken sheds preferentially caught either male or female Lu. longipalpis (Wilcoxon signed rank test, $P=0.188$ ) and there was no indication that any month was more effective than the others for trapping males or females for either of the insecticide treated (netting or spray) traps (Kruskal-Wallis test, $P=0.174$ ).

The average mortality for the netting treated sheds was $85 \%$ and for spray treated sheds $96 \%$. There was no significant difference in the numbers of Lu. longipalpis dead at 24h in the netting (1013) or spray (834) treated experimental sheds (Wilcoxon signed-rank test, $P=0.110$ ).

The age of the treatment (netting and spray) had a significant effect on the number of dead $L u$. longipalpis at 24h (Kruskal-Wallis, $P=0.000$ ). This effect was notable in the netting treated traps for both males $(P=0.000)$ and females $(P=0.002)$. However, in spray treated sheds age of the treatment was only a significant factor for females $(P=0.014)$ but not for males $(P=0.24)$. The effect was most obvious in September when the proportion of males and females that were dead at $24 \mathrm{~h}$ was approximately $60 \%$ in the net traps compared to compared to $90 \%$ in the spray traps. (Table 2, Fig 2).

Fig. 2 Mean number of Lutzomyia longipalpis, females and males, captured and dead after 24 hrs in May, July and August, after exposure to either a-cypermethrin impregnated netting or l-cyhalothrin residual spray.

\section{Insert Figure 2}

Although there was no significant difference in the numbers of Lu. longipalpis trapped throughout the experiment, the effectiveness of the netting in September appeared to be reduced compared to the spray. Thus, there was a significant reduction in the proportion of $L u$. longipalpis females dead at $24 \mathrm{~h}$ in the netting treatment compared to spray (i.e. $64 \%$ vs $96 \%$; Kruskall Wallis $P=0.000$ ) and also for males ( $89 \%$ vs $100 \%$; Kruskall Wallis $P=0.000$ ). (By comparison in both May and July almost $100 \%$ of the sand flies caught were dead at $24 \mathrm{~h}$ ).

The results suggest that initially (during May and July) the a-cypermethrin impregnated netting and Icyhalothrin residual spray were equally good at killing both male and female sand flies. However, the effectiveness of the netting treatment deteriorated over time so that in September significantly fewer male and female sand flies were killed by the compared to the spray treatment (Kruskal Wallis Test $P=0.004)$. 


\section{Experiment 3}

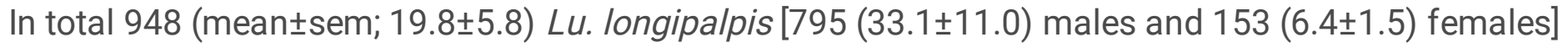
were collected before and after intervention in real chicken sheds during 12 nights in May 2019 (Table 3).

\section{Insert Table 3}

The overall ratio of males:females was 5.2:1. In the a-cypermethrin impregnated netting treated chicken

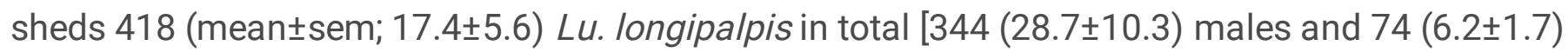
females] were collected before and after the intervention. In the l-cyhalothrin spray treated chicken sheds

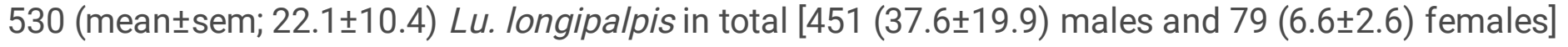
were collected before and after the intervention.

Before the netting intervention 235 males and 37 females were caught and afterwards 109 (proportion pre-intervention catch: post-intervention catch $=0.46)$ males and $37(1.0)$ females. Before the spray intervention 285 males and 51 females were caught and afterwards $166(0.58)$ males and $28(0.55)$ females.

Significantly more males than females were collected prior to the interventions (Wilcoxon signed-rank test; netting $P=0.005$, spray $P=0.005$ ) and similarly, after the interventions, significantly more males than females were collected (Wilcoxon-signed-rank test; netting $P=0.044$, spray $P=0.029$ ).

In this experiment only the netting intervention increased the proportion of females killed. The spray intervention did not increase the proportion of either males or females killed.

\section{Netting treatment, male Lu. longipalpis}

Before the netting intervention was applied the proportion of male flies dead after $24 \mathrm{~h}$ compared to the number collected was $70 \%(164 / 235)$. After the intervention the proportion of males flies dead at $24 \mathrm{~h}$ was not significantly different $79 \%(85 / 109)$ (Fisher's exact test $P=0.122)$.

\section{Netting treatment, female Lu. longipalpis}

Before the netting intervention was applied the proportion of female flies dead after $24 \mathrm{~h}$ compared to the number collected was $60 \%(22 / 37)$ and after the intervention the proportion of females flies dead was marginally significantly greater $81 \%(30 / 37)$ (Fisher's exact test $P=0.042)$.

\section{Spray treatment, male Lu. longipalpis}

Before the spray intervention the proportion of male flies dead after $24 \mathrm{~h}$ compared to the number collected was $66 \%(187 / 285)$ and afterwards the proportion of males flies dead was significantly lower, $55 \%(92 / 166)$ (Fisher's exact test $\mathrm{P}=0.032)$.

\section{Spray treatment, female Lu. longipalpis}


Before the spray intervention was applied the proportion of female flies dead after $24 \mathrm{~h}$ compared to the number collected was $73 \%$ (37/51) and after the intervention the proportion of females flies dead was not significantly different $54 \%(15 / 28)$ (Fisher's exact test $P=0.089)$.

Significantly less males were killed in chicken sheds treated with netting or spray than were caught (Wilcoxon Signed Ranks Test; mean caught $=17.6 \pm 6.2 \mathrm{vs}$ mean dead $=13.0 \pm 5.4 P=0.026$ ). (Wilcoxon Signed Ranks Test; mean caught $=31.8 \pm 24.6 \mathrm{vs}$ mean dead $=17.2 \pm 12.2 P=0.042$ ). There was no significant difference in the numbers of females killed and numbers caught in either intervention.

This result suggests that the insecticide treatments were having a greater effect on the females than the males.

The total number of males was significantly greater than the number of females for both netting and spray treated sheds (Wilcoxon Signed Ranks Test: $P<0.05$ ). Although the data set was small there was no indication that the house location contributed to the experimental outcome (Kruskal Wallis Test; $P=n s$ ).

\section{Experiment 4}

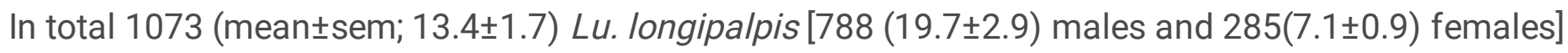
were collected before and after intervention during a 20-night period from August to September 2019 (Table 4). The overall ratio of males:females was 2.8:1.

\section{Insert Table 4}

In the boxes assigned to the a-cypermethrin impregnated netting treatment, 519 (mean \pm sem; 13.0 \pm 2.7 ) Lu. longipalpis in total [395 (19.8 \pm 4.9$)$ males and $124(6.2 \pm 1.1)$ females] were collected before and after the intervention. In the boxes assigned to the l-cyhalothrin spray treatment, 554 (mean \pm sem; 13.9 \pm 2.0 )

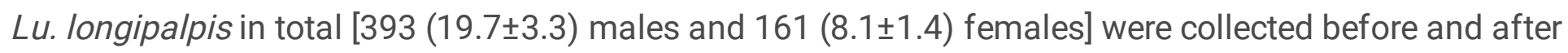
the intervention. Thus, the numbers of Lu. longipalpis (males and females and proportions) were similar for both the netting and spray treated elements of the experiment.

Application of the netting intervention significantly increased the proportions of both males and females dead after $24 \mathrm{~h}$ compared to before the intervention. The spray intervention also significantly increased the proportion of females dead after $24 \mathrm{~h}$ but did not affect the proportion of males dead after $24 \mathrm{~h}$.

\section{Netting treatment, male Lu. longipalpis}

Before the netting intervention the proportion of male flies dead after $24 \mathrm{~h}$ compared to the number collected was $56 \%(154 / 277)$. After the intervention the proportion of males flies dead was significantly greater, $86 \%(102 / 118)$ (Fisher's exact test $\mathrm{P}<0.0001)$.

\section{Netting treatment, female Lu. longipalpis}


Before the netting intervention the proportion of female flies dead after $24 \mathrm{~h}$ compared to the number collected was $60 \%$ (44/73) and after the intervention the proportion of female flies dead was marginally significantly greater $80 \%(41 / 51)$ (Fisher's exact test $P=0.0194)$.

\section{Spray treatment, male Lu. longipalpis}

Before the spray intervention the proportion of male flies dead after $24 \mathrm{~h}$ compared to the number collected was $62 \%[97 / 156]$ ) and after the intervention the proportion of male flies dead after $24 \mathrm{~h}$ compared to the number collected (70\% [167/237]) (Fisher's exact test; $P=0.0997)$.

\section{Spray treatment, female Lu. longipalpis}

The proportion of female flies dead after $24 \mathrm{~h}$ compared to the number collected before the spray intervention (43\% [33/76]) and was not significantly different to the proportion of females flies dead after the intervention (72\% [61/85]) (Fisher's exact test $P=0.0004)$.

Overall these results indicate that the netting and spray insecticide interventions have similar impacts on the population of Lu. longipalpis that are caught in the traps.

\section{Control traps}

Both Lu. longipalpis (98.4\%) and Evandromyia cortelezzii (1.6\%) were trapped in the control traps placed in houses A and B, however, only the numbers of Lu. longipalpis are reported in Table 5.

\section{Insert Table 5}

In total 414 (mean \pm sem; 6.5 \pm 0.9$)$ Lu. longipalpis [266 (8.3 \pm 1.5$)$ males and $148(4.6 \pm 0.8)$ females)] were collected in a total of 16 nights of trapping at both sites. Neither the male nor female trap counts were normally distributed (Shapiro-Wilk $\mathrm{P}=0.001$; Kolmogorov-Smirnov $\mathrm{P}=0.003$ ). Although fewer male flies were trapped in September than in the other months (Kruskal-Wallis $P=0.033$ ), more males than females were trapped in both houses (Wilcoxon signed-rank test: house $A, P=0.012$, house $B, P=0.037$ ). Also, there was no significant difference (Wilcoxon signed-rank test) in numbers of flies caught in house A compared to house B. The overall ratio of males:females caught was 1.8:1.

The control experiment showed that trapping was not a significant cause of mortality to either male or female Lu. longipalpis, we found no significant difference in the number of males $(72 \%)$ or females $(68 \%)$ alive after $24 \mathrm{~h}$ compared to the numbers initially caught (Fisher's exact test on a $2 \times 2$ sex-mortality table $P=0.43$, and chi-square test $P=0.40$ ).

\section{Discussion}

In these experiments we showed that insecticide treated netting was as effective as sprayed insecticide overall in killing female and male Lutzomyia longipalpis sand flies in both experimental and real chicken sheds when co-located with synthetic sex aggregation pheromone (S)-9-methylgermacrene-B. Insecticide 
treated netting is widely available as it is used in bed-nets for malaria control and although there are concerns over its misuse[36] the potential of insecticide impregnated materials including netting has also been recognised and evaluated for use in crop protection[37,38]. The experiments did not differentiate between the effectiveness of the different insecticides we investigated only the mode of their delivery; either in a spray or in a netting formulation.

The insecticides that we used are widely used for vector control in Brazil and Africa countries. The Icyhalothrin and a-cypermethrin are recommended by the Brazilian $\mathrm{MoH}$ for Lu. longipalpis control[5]. The Interceptor ${ }^{\circledR}$ netting used in experiments 1 and 2 is a surface treated, controlled release formulation of acypermethrin used in Brazil for malaria vector control[39] and Tanzania against Anopheles gambiae[40]. Olyset Plus netting is a LLIN in which the active ingredients permethrin and piperonyl butoxide are impregnated into the polyethylene fibres of the netting during manufacture and is currently being evaluated for use against malaria vectors in Africa where insecticide resistance is a problem[41].

In experiment 1 with experimental chicken sheds we found that the numbers of females collected and dead at $24 \mathrm{~h}$ was not statistically different in insecticide sprayed sheds compared to the netting treated sheds. By contrast significantly more males were caught (and dead at 24h) in the netting treated sheds compared to the spray treated sheds. The differential effect of insecticide on males compared to females has been previously observed in other studies[18, 42]. The difference has been ascribed to the relatively smaller size of the males making them more susceptible to the insecticides than females[42]. However, it may also be that in our experiments these differences are related to the different behaviours of the males and females in the proximity of hosts as well differences in the "knock-down" effect of the insecticide treatments. Males rest on the surfaces near the blood meal source where they defend territories and when females enter these territories they mate[15,43]. Thus, the males are likely to be in contact with the insecticide treated surfaces for longer than the females and thus may be disproportionately affected by the insecticide. The spray treatment has a greater knockdown effect on both males and females but because the females are not in contact with the insecticide treated surface for as long as males, they may pick up a lower dose of insecticide which makes them more likely to be caught in the trap. In our study, we only accounted for those Lu. longipalpis that entered the suction traps, we did not count those sand flies that might have been affected by insecticide and knocked down before entering the trap. Given the irregular construction of the real chicken sheds and the multiple opportunities for evasion of capture after exposure to insecticide the methodology utilised in other studies[44] would seem impractical although it could potentially provide very useful information in the experimental chicken shed experiments if the collecting sheet was separated from the chicken.

Another possible explanation for the reduced number of Lu. longipalpis in the spray (compared to netting) treated chicken sheds (both experimental and real) may be related to the relative repellent effect of the insecticides i.e. the spray treatment moved sand flies away from the HP traps. Repellence can be an advantage of pyrethroids, which is useful in reducing insect contact with the individual and thus offering personal protection against bites[45]. However, in a community vector control program the repellent effect of spraying may be to divert the sand flies to untreated places. 
In experiment 2 initially the same pattern of catches and lethality was observed as in experiment 1, i.e. there was no significant difference between the netting and spray treatments the difference in the effect of the treatments on both females and males became more pronounced over time when the acypermethrin netting became significantly less effective at killing both males and females compared to the I-cyhalothrin spray treatment. As initially the netting was as effective as spray for the first 2 months the deterioration was likely related to the effectiveness of the netting rather than a change in the response of the sand flies to the traps. However, it is unclear why the a-cypermethrin netting became less effective over time in our experiments. In field-scale evaluations this netting when used indoors has been found to be durable and effective against the malaria vectors, Anopheles culicifacies in India [46] and A. gambiae in Tanzania where $80 \%$ of the nets met WHOPES Phase III activity criteria at 36 months[40]. In our experiments the netting and I-cyhalothrin spray treatments remained in the experimental chicken sheds throughout the day and between experimental replicates were stored outside where they were exposed to UV light, fluctuating heat, humidity and rainwater. Although there is some evidence to suggest that acypermethrin degrades in UV[47] other studies have shown that repeated exposure to UV did not reduce the efficacy of the Interceptor netting[48]. In addition, the surface on which the insecticide is applied plays a significant role in determining the effectiveness of the insecticide treatment[42, 49, 50]. In addition, although the present study did not evaluate this aspect, as the netting was placed on a plywood substrate, its efficacy could have been affected by either the possible exposure to fungal growth encouraged by the proximity to damp wood or the interaction between the I-cypermethrin and the constituents of the plywood.

Experiments 3 and 4 demonstrated that when carried out in real chicken sheds the effect of the netting insecticide was similar to that of the sprayed insecticide. This suggests that the approach of treating real chicken sheds with insecticide treated netting to reduce sand flies is potentially valuable.

In both sets of experiments, in the experimental and real chicken sheds, the netting performed as well as the spray treatments. The concentration of insecticide that the sand flies were exposed to in the different treatments was variable and does not appear to have affected this outcome. Generally, the amount of insecticide that the sand flies were exposed to in the spray treatments was greater than that in the impregnated nets. Although $1 \mathrm{~m}^{2}$ of Olyset Plus ${ }^{\circledR}$, netting impregnated with permethrin $(20 \mathrm{~g} / \mathrm{kg})$ has 800 $\mathrm{mg}$ of ai it is released over the lifetime of the net which can be up to 3 years or longer. Therefore, the amount of insecticide present on the surface at any given time is very small. By comparison $1 \mathrm{~m}^{2}$ of acypermethrin spray treated surface had $40 \mathrm{mg}$ of a.i. Similarly, $1 \mathrm{~m}^{2}$ of Interceptor ${ }^{\circledR}$ netting treated with acypermethrin has $200 \mathrm{mg}$ of a.i. bound to the surface of the netting fibres and this is used over 3 years or longer, it is not replenished from a central reservoir during the lifetime of the netting as with impregnated netting. The microencapsulated I-cyhalothrin treatment had $20 \mathrm{mg}$ of a.i. In addition, there are differences in the effectiveness of the different insecticides for example permethrin is $10 x$ more potent than $1-$ cyhalothrin.

According to the World Health Organisation LLINs are cost-effective for reducing the transmission and burden of malaria[51]. However, evidence for the conventional use of insecticide impregnated bed nets to 
reduce VL transmission is contradictory. A small scale trial in Bangladesh showed a $66.5 \%$ reduction of VL cases[52], in Sudan the use of insecticide treated bed nets reduced VL by $59 \%$ [53] and the use of Olyset Plus impregnated netting showed a significant reduction in incidence rate $(4.78 \%$ to $0.37 \%)$ of cutaneous leishmaniasis in a hyperendemic area in Turkey[54]. However a large scale community trial carried out in India and Nepal contradict these findings and suggest that large scale usage of long-lasting insecticidal nets provided no additional protection against visceral leishmaniasis compared with existing control practice[55]. A significant problem with the conventional use for personal use of insecticide impregnated netting in VL control is that most female sand flies $(>50 \%)$ bite in the early evening (18:00$21: 00)$ meaning that the majority of the human population is not sleeping under, and thus is not protected by the nets [54-56].

The possibility of using permethrin-impregnated netting as an alternative to a micro-encapsulated Icyhalothrin surface treatment against female Lu. longipalpis was first tested in a laboratory study[27].

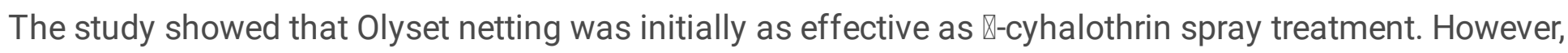
whereas the netting remained nearly $100 \%$ lethal $24 \mathrm{~h}$ post exposure for 12 months the effectiveness of the residual insecticide declined to approximately $74 \%$ over $6-12$ months. The reduction in the effectiveness of the residual spray treatment was similar to that observed against the cutaneous leishmaniasis vector Lu. verrucarum when sprayed on outside walls in Peru[57] and Olyset Plus netting has been shown to remain fully active for at least 1 year in field conditions[54]. It was also noted that initially the immediate mortality of the netting was significantly lower than that of the l-cyhalothrin spray. The netting killed on average $13.5 \% \pm 1.3$ (mean \pm SEM) of exposed sand flies immediately following $1 \mathrm{~h}$ of exposure whereas the spray killed $56 \% \pm 3$.9. However, the immediate lethality of the netting remained relatively constant over the 12 months of the study whereas the immediate lethality of the spray treatment decreased to around $10-12 \%$ over 12 months. In practice the Brazilian $\mathrm{MoH}$ recommend that insecticide spray treatment is reapplied after 3 to 4 months[5].

This study showed for the first time in field experiments that long-lasting insecticide impregnated netting could be used against $L u$. longipalpis sand flies as an alternative to residual insecticide spraying. The approach is potentially cost-effective, simple to apply and can be combined with synthetic sex/aggregation pheromone to provide a readily accessible intervention measure for leishmaniasis control[58].

Other studies have demonstrated the efficacy of impregnated netting and other materials against endophilic sand flies[59, 60]. However, this strategy, directed against exophilic Lu. longipalpis abundant in peridomestic environments is a new approach. The possible population effects of the use of netting against sand flies are still unknown and more detailed studies involving bioassays and susceptibility tests comparing the same insecticides and concentrations in residual spray and impregnated nets, as well as longer lasting field experiments in sand flies resting sites (e.g. chicken sheds) are essential to understand the effectiveness of these strategies in controlling leishmaniasis. In any case, for leishmaniasis control, the regular spraying of all potential aggregation sites in Brazil, particularly in rural communities is impractical[61]. 
More extensive trials that co-locate insecticide impregnated net and synthetic sex/aggregation pheromone are required to determine the effectiveness of this approach in an "attract-and-kill" strategy to improve sand fly control. A trial of synthetic ( \pm -9-9-methylgermacrene-B[25] formulated in a long-lasting controlled release device[26,27] co-located with microencapsulated I-cyhalothrin in chicken roosting sites significantly reduced Lu. longipalpis densities, canine Leishmania parasite infection incidence, tissue loads and canine seroconversion incidence [23] indicating the potential of this strategy for reducing disease incidence however replacing the sprayed insecticide application with a netting application could improve the cost of the application and therefore coverage.

\section{Conclusions}

The main objective of these experiments was to investigate the feasibility of using netting rather than spraying as an insecticide treatment in chicken sheds alongside Lu. longipalpis synthetic sex aggregation pheromone. The application of insecticide treated netting for $L u$. longipalpis control has several potential important advantages over residual insecticide spraying, these include; accurate dose control, ease of application (reduced training with no requirement for specialist spraying equipment), personnel and environmental safety, reduced costs and longevity of treatment. The application of a single piece of insecticide impregnated netting (or other insecticide pre-treated surface) along with synthetic sex pheromone could provide a cost-effective means of Lu. longipalpis control. Our results indicate that netting has the potential to replace spraying as a means of delivering insecticide for vector control and consequent reduction of disease transmission. However, more work is needed to investigate the long-term effectiveness of this strategy as part of a control program applied in animal sheds and other $L u$. longipalpis aggregation sites, in combination with synthetic sex aggregation pheromone.

\section{Abbreviations}

ANA: Agência Nacional de Águas; APA: Área de Preservação Ambiental; GC/MS: gas chromatographymass spectrometry; GV: Governador Valadares; HP: Hoover Pugedo; ITN: Insecticide-impregnated/treated netting; IBGE: Instituto Brasileiro de Geografia e Estatistica; MoH: Ministry of Health; PBO: piperonyl butoxide; SIRGAS: Sistema de Referência Geocêntrico; UTM: Universal Transverse Mercator; VL: visceral leishmaniasis.

\section{Declarations}

\section{Acknowledgements}

We are grateful to the owners of the homes where the studies took place for allowing us access to their properties and to the Centro de Controle de Zoonoses (CCZ) for giving us permission to carry out this study in Governador Valadares. We thank Dr. Wallace Beiroz for helping with a preliminary version of the experiments in real chicken sheds. We also thank Dave Malone and John Invest of Sumitomo Chemical Company UK Ltd. for the gift of Olyset Plus insecticide impregnated netting. 


\section{Ethics approval and consent to participate}

The project, including the involvement of householders, was reviewed and approved by the Faculty of Health and Medicine Ethical Review Committee (FHMREC15125) at Lancaster University. This study was carried out in accordance with the guidelines of the Animals in Science Regulation Unit (ASRU) and in compliance with the Animals (Scientific Procedures) Act (ASPA) 1986 (amended 2012) regulations and was consistent with UK Animal Welfare Act 2006 and The Welfare of Farmed Animals (England)

Regulations 2007 and 2010. Oral consent was obtained from the Governador Valadares health authority (CCZ) to conduct the study within their administrative jurisdiction and from the householders for use of their animals and property.

\section{Consent for publication}

Not applicable

\section{Availability of data and materials}

All data generated or analysed during this study are included in this published article and its additional information files.

\section{Competing interests}

The authors declare that they have no competing interests

\section{Funding}

VAB was funded by the Coordenação de Aperfeiçoamento de Pessoal de Nível Superior (CAPES). RPB was funded by the Conselho Nacional de Desenvolvimento Científico e Tecnológico (CNPq). JGCH was funded by The Wellcome Trust (080961/Z/06/Z).

The funding bodies played no role in the design of the study, or collection, analysis, and interpretation of data. They played no role in writing the manuscript.

\section{Authors' contributions}

VAB designed experiments 1 and 2, acquired and interpreted the data, drafted and substantially revised the manuscript. CFS designed all experiments and acquired the data. DG analysed and interpreted the data. RPB conceived the study and designed the experiments. JGCH conceived the study, designed the experiments, interpreted the data, drafted and substantially revised the manuscript. All authors read, contributed to and approved the final manuscript.

\section{References}


1. WHO. Leishmaniasis 2019 [cited 2019 19th August 2019]. Available from: https://www.who.int/leishmaniasis/en/.

2. PAHO/WHO. Leishmaniasis: Epidemiological Report in the Americas2018; 6:[7 p.]. Available from: http://iris.paho.org/xmlui/handle/123456789/34856.

3. Casanova C, Colla-Jacques FE, Hamilton JG, Brazil RP, Shaw JJ. Distribution of Lutzomyia longipalpis chemotype populations in Sao Paulo state, Brazil. PLoS neglected tropical diseases. 2015;9(3):e0003620. Epub 2015/03/18. doi: 10.1371/journal.pntd.0003620. PubMed PMID: 25781320; PubMed Central PMCID: PMCPMC4363371.

4. Brazil RP. The dispersion of Lutzomyia longipalpis in urban areas. Revista da Sociedade Brasileira de Medicina Tropical. 2013;46:263-4.

5. Ministério da Saúde B. Manual de vigilância e controle da leishmaniose visceral. In: Epidemiológica SdVeSDdV, editor. 1 ed. Brasília: Ministério da Saúde.; 2014. p. 120.

6. Dantas-Torres F, Solano-Gallego L, Baneth G, Ribeiro VM, de Paiva-Cavalcanti M, Otranto D. Canine leishmaniosis in the Old and New Worlds: unveiled similarities and differences. Trends Parasitol. 2012;28(12):531-8. Epub 2012/09/22. doi: 10.1016/j.pt.2012.08.007. PubMed PMID: 22995719.

7. Courtenay O, Quinnell RJ, Garcez LM, Shaw JJ, Dye C. Infectiousness in a cohort of Brazilian dogs: Why culling fails to control visceral leishmaniasis in areas of high transmission. Journal of Infectious Diseases. 2002;186(9):1314-20. doi: 10.1086/344312. PubMed PMID: WOS:000178577500014.

8. Harhay MO, Olliaro PL, Costa DL, Costa CHN. Urban parasitology: visceral leishmaniasis in Brazil. Trends in Parasitology. 2011;27(9):403-9. doi: https://doi.org/10.1016/j.pt.2011.04.001.

9. Costa $\mathrm{CHN}$. How effective is dog culling in controlling zoonotic visceral leishmaniasis? a critical evaluation of the science, politics and ethics behind this public health policy. Revista da Sociedade Brasileira de Medicina Tropical. 2011;44:232-42.

10. Costa DN, Codeco CT, Silva MA, Werneck GL. Culling dogs in scenarios of imperfect control: realistic impact on the prevalence of canine visceral leishmaniasis. PLoS neglected tropical diseases. 2013;7(8):e2355. Epub 2013/08/21. doi: 10.1371/journal.pntd.0002355. PubMed PMID: 23951375; PubMed Central PMCID: PMCPMC3738479.

11. Podaliri Vulpiani M, lannetti L, Paganico D, lannino F, Ferri N. Methods of Control of the Leishmania infantum Dog Reservoir: State of the Art. Veterinary Medicine International. 2011;2011. doi: $10.4061 / 2011 / 215964$.

12. Martins-Melo FR, Carneiro M, Ramos AN, Jr., Heukelbach J, Ribeiro ALP, Werneck GL. The burden of Neglected Tropical Diseases in Brazil, 1990-2016: A subnational analysis from the Global Burden of Disease Study 2016. PLoS neglected tropical diseases. 2018;12(6):e0006559. Epub 2018/06/05. doi: 10.1371/journal.pntd.0006559. PubMed PMID: 29864133; PubMed Central PMCID: PMCPMC6013251.

13. Alexander B, Barros VC, De Souza SF, Barros SS, Teodoro LP, Soares ZR, et al. Susceptibility to chemical insecticides of two Brazilian populations of the visceral leishmaniasis vector Lutzomyia 
longipalpis (Diptera: Psychodidae). Tropical Medicine \& International Health. 2009;14(10):1272-7. doi: 10.1111/j.1365-3156.2009.02371.x.

14. Chowdhury R, Huda MM, Kumar V, Das P, Joshi AB, Banjara MR, et al. The Indian and Nepalese programmes of indoor residual spraying for the elimination of visceral leishmaniasis: performance and effectiveness. Ann Trop Med Parasitol. 2011;105(1):31-5. Epub 2011/02/08. doi: 10.1179/136485911X12899838683124. PubMed PMID: 21294947; PubMed Central PMCID: PMCPMC4089790.

15. Kelly DW, Dye C. Pheromones, kairomones and the aggregation dynamics of the sandfly Lutzomyia longipalpis. Animal Behaviour. 1997;53:721-31. doi: 10.1006/anbe.1996.0309. PubMed PMID: WOS:A1997WW45300005.

16. Spiegel CN, Dias DB, Araki AS, Hamilton JG, Brazil RP, Jones TM. The Lutzomyia longipalpis complex: a brief natural history of aggregation-sex pheromone communication. Parasit Vectors. 2016;9(1):580. Epub 2016/11/16. doi: 10.1186/s13071-016-1866-x. PubMed PMID: 27842601; PubMed Central PMCID: PMCPMC5109651.

17. Bell MJ, Sedda L, Gonzalez MA, de Souza CF, Dilger E, Brazil RP, et al. Attraction of Lutzomyia longipalpis to synthetic sex-aggregation pheromone: Effect of release rate and proximity of adjacent pheromone sources. PLoS neglected tropical diseases. 2018;12(12):e0007007. Epub 2018/12/20. doi: 10.1371/journal.pntd.0007007. PubMed PMID: 30566503; PubMed Central PMCID: PMCPMC6300254.

18. Kelly DW, Mustafa Z, Dye C. Differential application of lambda-cyhalothrin to control the sandfly Lutzomyia longipalpis. Medical and Veterinary Entomology. 1997;11(1):13-24. doi: 10.1111/j.13652915.1997.tb00285.x. PubMed PMID: WOS:A1997WK47000004.

19. Bray DP, Alves GB, Dorval ME, Brazil RP, Hamilton JG. Synthetic sex pheromone attracts the leishmaniasis vector Lutzomyia longipalpis to experimental chicken sheds treated with insecticide. Parasit Vectors. 2010;3:16. Epub 2010/03/13. doi: 10.1186/1756-3305-3-16. PubMed PMID: 20222954; PubMed Central PMCID: PMCPMC2850890.

20. Bray DP, Bandi KK, Brazil RP, Oliveira AG, Hamilton JG. Synthetic sex pheromone attracts the leishmaniasis vector Lutzomyia longipalpis (Diptera: Psychodidae) to traps in the field. J Med Entomol. 2009;46(3):428-34. Epub 2009/06/06. PubMed PMID: 19496409; PubMed Central PMCID: PMCPMC3197723.

21. Bray DP, Carter V, Alves GB, Brazil RP, Bandi KK, Hamilton JG. Synthetic sex pheromone in a longlasting lure attracts the visceral leishmaniasis vector, Lutzomyia longipalpis, for up to 12 weeks in Brazil. PLoS neglected tropical diseases. 2014;8(3):e2723. Epub 2014/03/22. doi: 10.1371/journal.pntd.0002723. PubMed PMID: 24651528; PubMed Central PMCID: PMСРMC3961206.

22. Gonzalez MA, Bandi KK, Bell MJ, Brazil RP, Dilger E, Guerrero A, et al. A temporal comparison of sexaggregation pheromone gland content and dynamics of release in three members of the Lutzomyia longipalpis (Diptera: Psychodidae) species complex. PLoS neglected tropical diseases. 
2017;11(12):e0006071. Epub 2017/12/02. doi: 10.1371/journal.pntd.0006071. PubMed PMID: 29194438; PubMed Central PMCID: PMCPMC5745125.

23. Gonzalez MA, Bell MJ, Bernhardt SA, Brazil RP, Dilger E, Courtenay O, et al. Susceptibility of wildcaught Lutzomyia longipalpis (Diptera: Psychodidae) sand flies to insecticide after an extended period of exposure in western Sao Paulo, Brazil. Parasit Vectors. 2019;12(1):110. Epub 2019/03/16. doi: 10.1186/s13071-019-3364-4. PubMed PMID: 30871639; PubMed Central PMCID: PMCPMC6419423.

24. Krishnakumari BSR, K.; Hamilton, J.G.C. Synthesis of 9-methylgermacrene from germacrone, an active analogue of (S)-9-methylgermacrene-B, sex pheromone of Phlebotomine sandfly, Lutzomyia longipalpis, from Lapinha Brazil. IUPAC International Conference on Biodiversity and Natural Products: Chemistry and Medical Applications (combining ICOB-4 and ISCNP-24);; 26-31 January 2004.; Delhi, India.2004.

25. Courtenay O, Dilger E, Calvo-Bado LA, Kravar-Garde L, Carter V, Bell MJ, et al. Sand fly synthetic sexaggregation pheromone co-located with insecticide reduces the incidence of infection in the canine reservoir of visceral leishmaniasis: A stratified cluster randomised trial. PLoS neglected tropical diseases. 2019;13(10):e0007767. doi: 10.1371/journal.pntd.0007767.

26. WHO. Global vector control response 2017-2030. Geneva: 2017 Contract No.: CC BY-NC-SA 3.0 IGO.

27. Bray DP, Hamilton JG. Insecticide-impregnated netting as a potential tool for long-lasting control of the leishmaniasis vector Lutzomyia longipalpis in animal shelters. Parasit Vectors. 2013;6:133. Epub 2013/05/07. doi: 10.1186/1756-3305-6-133. PubMed PMID: 23642213; PubMed Central PMCID: PMCPMC3658972.

28. Barata RA, Peixoto JC, Tanure A, Gomes ME, Apolinario EC, Bodevan EC, et al. Epidemiology of visceral leishmaniasis in a reemerging focus of intense transmission in Minas Gerais State, Brazil. Biomed Res Int. 2013;2013:405083. Epub 2013/09/04. doi: 10.1155/2013/405083. PubMed PMID: 24000322; PubMed Central PMCID: PMCPMC3755404.

29. Valdivia HO, Almeida LV, Roatt BM, Reis-Cunha JL, Pereira AA, Gontijo C, et al. Comparative genomics of canine-isolated Leishmania (Leishmania) amazonensis from an endemic focus of visceral leishmaniasis in Governador Valadares, southeastern Brazil. Sci Rep. 2017;7:40804. Epub 2017/01/17. doi: 10.1038/srep40804. PubMed PMID: 28091623; PubMed Central PMCID: PMCPMC5238499.

30. Peel MC, Finlayson BL, McMahon TA. Updated world map of the Köppen-Geiger climate classification. Hydrol Earth Syst Sci. 2007;11(5):1633-44. doi: 10.5194/hess-11-1633-2007.

31. Climate-data.org. Climate data for cities worldwide - Climate: Governador Valadares 2017 [cited 2017 13th October 2017]. Available from: https://en.climate-data.org/info/sources/.

32. Hamilton JG, Maingon RD, Alexander B, Ward RD, Brazil RP. Analysis of the sex pheromone extract of individual male Lutzomyia longipalpis sandflies from six regions in Brazil. Med Vet Entomol. 2005;19(4):480-8. Epub 2005/12/13. doi: 10.1111/j.1365-2915.2005.00594.x. PubMed PMID: 16336313. 
33. Mangabeira Filho O. Sobre a sistemática e biologia dos Phlebotomus do Ceará. Revista Brasileira de Malariologia e Doencas Tropicais. 1969;21:21.

34. Galati EAB. Morfologia e taxonomia: classificaçao de phlebotominae. Flebotomíneos do Brasil. Rio de Janeiro: Fiocruz; 2003.

35. Pugedo H, Barata RA, França-Silva JC, Silva JC, Dias ES. HP: um modelo aprimorado de armadilha luminosa de sucção para a captura de pequenos insetos. Revista da Sociedade Brasileira de Medicina Tropical. 2005;38:70-2.

36. Berthe S, Harvey SA, Lynch M, Koenker H, Jumbe V, Kaunda-Khangamwa B, et al. Poverty and food security: drivers of insecticide-treated mosquito net misuse in Malawi. Malaria Journal. 2019;18(1):320. doi: 10.1186/s12936-019-2952-2.

37. Dáder B, Legarrea S, Moreno A, Ambros CM, Fereres A, Viñuela E, et al., editors. Insecticide-Treated Nets as a New Approach to Control Vegetable Pests

in Protected Crops. International CIPA Conference 2012 on Plasticulture for a Green Planet Tel Aviv, May 15-17, 2012; 2012; Tel Aviv. Acta Horticulturae: International Society for Horticultural Science (ISHS), Leuven, Belgium; 2014.

38. Marianelli L, Paoli F, Sabbatini Peverieri G, Benvenuti C, Barzanti GP, Bosio G, et al. Long-lasting insecticide-treated nets: A new integrated pest management approach for Popillia japonica (Coleoptera: Scarabaeidae). Integrated Environmental Assessment and Management. 2019;15(2):259-65. doi: 10.1002/ieam.4107.

39. BASF. Making a difference 2019 [cited 201912 November]. Available from: https://www.basf.com/za/en/media/Magazines/quality-of-life/making-a-difference.html.

40. Tungu P, Kirby M, Malima R, Kisinza W, Magesa S, Maxwell C, et al. Interceptor ${ }^{\circledR}$ long-lasting insecticidal net: phase III evaluation over three years of household use and calibration with Phase II experimental hut outcomes. Parasites \& Vectors. 2016;9(1):204. doi: 10.1186/s13071-016-1490-9.

41. WHO. Conditions for deployment of mosquito nets treated with a pyrethroid and piperonyl butoxide. World Health Organisation, 2017.

42. Dora Feliciangeli M, Mazzarri MB, Blas SS, Zerpa O. Control trial of Lutzomyia longipalpis s.I. in the Island of Margarita, Venezuela. Tropical Medicine \& International Health. 2003;8(12):1131-6. doi: 10.1046/j.1360-2276.2003.01137.x.

43. Morrison AC, Ferro C, Pardo R, Torres M, Wilson ML, Tesh RB. Nocturnal activity patterns of Lutzomyia longipalpis (Diptera, Psychodidae) at an endemic focus of visceral leishmaniasis in Colombia. Journal of Medical Entomology. 1995;32(5):605-17. doi: 10.1093/jmedent/32.5.605. PubMed PMID: WOS:A1995RT60800007.

44. DEL RÍO R, BARCELÓ C, PAREDES-ESQUIVEL C, LUCIENTES J, MIRANDA MA. Susceptibility of Culicoides species biting midges to deltamethrin-treated nets as determined under laboratory and field conditions in the Balearic Islands, Spain. Medical and Veterinary Entomology. 2014;28(4):41420. doi: $10.1111 /$ mve.12072. 
45. Kawada H, Ohashi K, Dida GO, Sonye G, Njenga SM, Mwandawiro C, et al. Insecticidal and repellent activities of pyrethroids to the three major pyrethroid-resistant malaria vectors in western Kenya. Parasites \& Vectors. 2014;7(1):208. doi: 10.1186/1756-3305-7-208.

46. Bhatt RM, Sharma SN, Uragayala S, Dash AP, Kamaraju R. Effectiveness and durability of Interceptor ${ }^{\circledR}$ long-lasting insecticidal nets in a malaria endemic area of central India. Malaria journal. 2012;11:189-. doi: 10.1186/1475-2875-11-189. PubMed PMID: 22682024.

47. World Health Organisation. Environmental Health Criteria 82, Cypermethrin. Geneva: 1989.

48. Ouattara JP, Louwagie J, Pigeon O, Spanoghe P. Comparison of the laboratory standard washing using CIPAC washing agent and the domestic washing on three recommended types of long-lasting insecticidal mosquito nets. PLoS One. 2013;8(10):e74824. Epub 2013/10/17. doi: 10.1371/journal.pone.0074824. PubMed PMID: 24130671; PubMed Central PMCID: PMCPMC3794022.

49. Mutagahywa J, ljumba JN, Pratap HB, Molteni F, Mugarula FE, Magesa SM, et al. The impact of different sprayable surfaces on the effectiveness of indoor residual spraying using a micro encapsulated formulation of lambda-cyhalothrin against Anopheles gambiae s.s. Parasit Vectors. 2015;8:203. Epub 2015/04/19. doi: 10.1186/s13071-015-0795-4. PubMed PMID: 25890339; PubMed Central PMCID: PMCPMC4392635.

50. Correa A, Galardo AKR, Lima LA, Camara DCP, Muller JN, Barroso JFS, et al. Efficacy of insecticides used in indoor residual spraying for malaria control: an experimental trial on various surfaces in a "test house". Malar J. 2019;18(1):345. Epub 2019/10/12. doi: 10.1186/s12936-019-2969-6. PubMed PMID: 31601226; PubMed Central PMCID: PMCPMC6785876.

51. World Malaria Report. Geneva: World Health Organisation, 2018.

52. Mondal D, Huda MM, Karmoker MK, Ghosh D, Matlashewski G, Nabi SG, et al. Reducing visceral leishmaniasis by insecticide impregnation of bed-nets, Bangladesh. Emerging infectious diseases. 2013;19(7):1131-4. doi: 10.3201/eid1907.120932. PubMed PMID: 23764246.

53. Ritmeijer K, Davies C, Van Zorge R, Wang S-J, Schorscher J, Dongu'du SI, et al. Evaluation of a mass distribution programme for fine-mesh impregnated bednets against visceral leishmaniasis in eastern Sudan. Tropical Medicine \& International Health. 2007;12(3):404-14. doi: 10.1111/j.13653156.2006.01807.x.

54. Gunay F, Karakus M, Oguz G, Dogan M, Karakaya Y, Ergan G, et al. Evaluation of the efficacy of Olyset ${ }^{\circledR}$ Plus in a village-based cohort study in the Cukurova Plain, Turkey, in an area of hyperendemic cutaneous leishmaniasis. Journal of Vector Ecology. 2014;39(2):395-405. doi: 10.1111/jvec.12115.

55. Picado A, Singh SP, Rijal S, Sundar S, Ostyn B, Chappuis F, et al. Longlasting insecticidal nets for prevention of Leishmania donovani infection in India and Nepal: paired cluster randomised trial. BMJ (Clinical research ed). 2010;341:c6760-c. doi: 10.1136/bmj.c6760. PubMed PMID: 21190965.

56. Courtenay O, Gillingwater K, Gomes PAF, Garcez LM, Davies CR. Deltamethrin-impregnated bednets reduce human landing rates of sandfly vector Lutzomyia longipalpis in Amazon households. Medical 
and Veterinary Entomology. 2007;21(2):168-76. doi: 10.1111/j.1365-2915.2007.00678.x. PubMed PMID: WOS:000247175100006.

57. Davies CR, Llanos-Cuentas EA, Campos P, Monge J, Leon E, Canales J. Spraying houses in the Peruvian Andes with lambda-cyhalothrin protects residents against cutaneous leishmaniasis. Transactions of The Royal Society of Tropical Medicine and Hygiene. 2000;94(6):631-6. doi: 10.1016/S0035-9203(00)90214-1.

58. Courtenay O, Dilger E, Calvo-Bado LA, Kravar-Garde L, Carter V, J. BM, et al. Sand fly synthetic sexaggregation pheromone co-located with insecticide reduces canine Leishmania infantum infection incidence: a stratified cluster randomised trial. BioRxiv. 2019. doi: https://doi.org/10.1101/712174.

59. Maroli M, Majori G. Permethrin-impregnated curtains against phlebotomine sandflies (Diptera: Psychodidae): laboratory and field studies. Parassitologia. 1991;33 Suppl:399-404. Epub 1991/12/01. PubMed PMID: 1841235.

60. Alexander B, Usma MC, Cadena H, Quesada BL, Solarte Y, Roa W, et al. Evaluation of deltamethrinimpregnated bednets and curtains against phlebotomine sandflies in Valle del Cauca, Colombia. Med Vet Entomol. 1995;9(3):279-83. Epub 1995/07/01. doi: 10.1111/j.1365-2915.1995.tb00134.x. PubMed PMID: 7548945.

61. Picado A, Dash AP, Bhattacharya S, Boelaert M. Vector control interventions for visceral leishmaniasis elimination initiative in South Asia, 2005-2010. Indian J Med Res. 2012;136(1):22-31. PubMed PMID: 22885260.

\section{Tables}

Table 1 Number of male and female Lu. longipalpis collected in experimental chicken sheds treated with either a-cypermethrin impregnated netting or l-cyhalothrin residual spray and their mortality after 24 hours. 


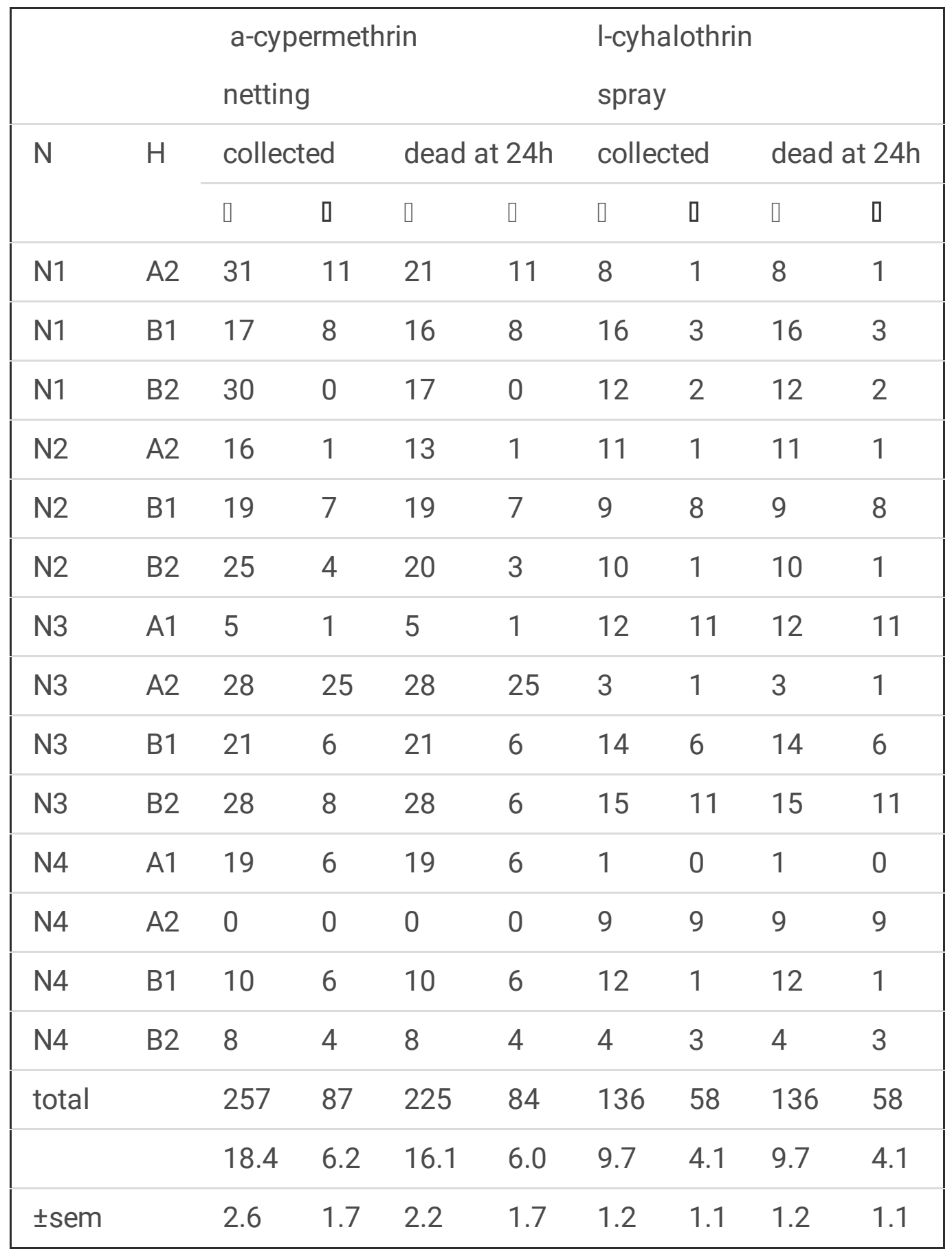

$N=$ nights $(1,2,3$ or 4$)=$ on which data were collected; $H$ = house $(A$ or $B)$ and pair (1 or 2$)$ in which the collection was made; collected $\nabla$ and $\mathrm{Q}=$ the number of $L u$. longipalpis, male and female collected by the

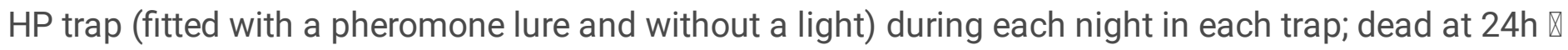
and $\mathbb{Q}=$ the number of males and females that were dead after $24 \mathrm{hrs}$; total = total number of $L u$.

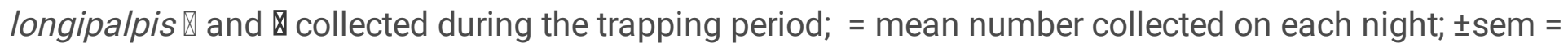
\pm standard error of the mean.

Table 2. Summary of number of male and female Lu. longipalpis caught in the experimental chicken sheds treated with either a-cypermethrin impregnated netting or l-cyhalothrin residual spray over a 5- 
month period in experiment 2 .

\begin{tabular}{|c|c|c|c|c|c|c|c|c|c|}
\hline & & \multicolumn{4}{|c|}{$\begin{array}{l}\text { a-cypermethrin } \\
\text { impregnated netting }\end{array}$} & \multicolumn{4}{|c|}{$\begin{array}{l}\text { I-cyhalothrin } \\
\text { residual spray }\end{array}$} \\
\hline & & \multicolumn{2}{|c|}{ collected } & \multicolumn{2}{|c|}{ dead at $24 \mathrm{~h}$} & \multicolumn{2}{|c|}{ collected } & \multicolumn{2}{|c|}{ dead at $24 \mathrm{~h}$} \\
\hline & & Q & प & Q & प & Q & 0 & प & प \\
\hline \multirow[t]{3}{*}{ May } & total & 280 & 107 & 276 & 100 & 151 & 67 & 151 & 67 \\
\hline & & 23.3 & 8.9 & 23.0 & 8.3 & 12.6 & 5.6 & 12.6 & 5.6 \\
\hline & \pm sem & 8.8 & 2.2 & 8.8 & 2.0 & 1.3 & 1.2 & 1.3 & 1.2 \\
\hline \multirow[t]{3}{*}{ July } & total & 339 & 108 & 323 & 101 & 256 & 107 & 255 & 106 \\
\hline & & 24.2 & 7.7 & 23.1 & 7.2 & 18.3 & 7.6 & 18.2 & 7.6 \\
\hline & \pm sem & 4.6 & 1.6 & 4.5 & 1.5 & 3.2 & 1.3 & 3.2 & 1.3 \\
\hline \multirow[t]{3}{*}{ Sept } & total & 231 & 103 & 162 & 51 & 184 & 101 & 163 & 92 \\
\hline & & 14.4 & 6.4 & 10.1 & 3.2 & 11.5 & 6.3 & 10.2 & 5.6 \\
\hline & \pm sem & 2.6 & 1.6 & 1.6 & 1.1 & 3.0 & 1.4 & 2.2 & 1.3 \\
\hline
\end{tabular}

total = the total number of Lu. longipalpis, male and (female) collected by the HP trap during each month; total dead $24 \mathrm{hr}=$ the total number dead after $24 \mathrm{hrs}$; = daily mean catch; \pm sem $= \pm$ standard error of the mean.

Table 3. Number of male and female Lu. longipalpis trapped in a longitudinal intervention trial (experiment 3) in an HP suction trap baited with pheromone (no light) in real chicken sheds treated with either a-cypermethrin impregnated netting or l-cyhalothrin residual spray. 


\begin{tabular}{|c|c|c|c|c|c|c|c|c|c|c|c|c|c|}
\hline & & befol & inter & ntion & & after & terve & tion & & & & & \\
\hline & & no in & ectici & & & a-cyp & rmetl & in nett & & I-cyh & pthrir & spray & \\
\hline & $\mathrm{H}$ & colle & & dead & t 24h & colles & & dead & $24 \mathrm{~h}$ & colle & & dead & $24 \mathrm{~h}$ \\
\hline & & [ & ૧ & [ & [ & ૫ & [ & [ & — & ૧ & [ & [ & ૫ \\
\hline R1 & 1 & 6 & 0 & 4 & 0 & 2 & 2 & 1 & 1 & - & - & - & - \\
\hline & 4 & 24 & 7 & 12 & 4 & 20 & 7 & 17 & 7 & - & - & - & - \\
\hline & 6 & 24 & 5 & 19 & 3 & 14 & 5 & 6 & 2 & - & - & - & - \\
\hline R2 & 2 & 44 & 7 & 31 & 4 & 21 & 6 & 20 & 5 & - & - & - & - \\
\hline & 3 & 3 & 1 & 2 & 0 & 12 & 0 & 9 & 0 & - & - & - & - \\
\hline & 5 & 134 & 17 & 96 & 11 & 40 & 17 & 32 & 15 & - & - & - & - \\
\hline total* & & 235 & 37 & 164 & 22 & 109 & 37 & 85 & 30 & - & - & - & - \\
\hline & & 39.2 & 6.2 & 27.3 & 3.7 & 18.2 & 6.2 & 14.2 & 5.0 & - & - & - & - \\
\hline \pm sem & & 19.9 & 2.5 & 14.4 & 1.7 & 5.2 & 2.4 & 4.6 & 2.3 & - & - & - & - \\
\hline R1 & 3 & 8 & 8 & 5 & 3 & - & - & - & - & 5 & 2 & 5 & 1 \\
\hline & 5 & 226 & 32 & 144 & 27 & - & - & - & - & 130 & 16 & 66 & 7 \\
\hline R2 & 1 & 8 & 1 & 6 & 1 & - & - & - & - & 7 & 1 & 5 & 0 \\
\hline & 4 & 30 & 5 & 19 & 1 & - & - & - & - & 12 & 3 & 6 & 3 \\
\hline & 6 & 1 & 2 & 1 & 2 & - & - & - & - & 5 & 0 & 4 & 0 \\
\hline & 7 & 12 & 3 & 12 & 3 & - & - & - & - & 7 & 6 & 6 & 4 \\
\hline total $^{\#}$ & & 285 & 51 & 187 & 37 & - & - & - & - & 166 & 28 & 92 & 15 \\
\hline & & 47.5 & 8.5 & 31.2 & 6.2 & - & - & - & - & 27.7 & 4.7 & 15.3 & 2.5 \\
\hline \pm sem & & 35.9 & 4.8 & 22.7 & 4.2 & - & - & - & - & 20.5 & 2.4 & 10.1 & 1.1 \\
\hline
\end{tabular}

$\mathrm{R}=$ experimental replicate; $\mathrm{H}=$ household in which the chicken shed was located; before intervention=number of male and female Lu. longipalpis trapped when no insecticide treatment was present ( $1^{\text {st }}$ night); after intervention=number of male and female $L u$. longipalpis trapped when either acypermethrin netting or l-cyhalothrin spray insecticide treatment was present in the chicken shed $\left(2^{\text {nd }}\right.$ night). Total* is the total number of sand flies caught and then dead after $24 \mathrm{~h}$ in all chicken sheds and on all nights after the a-cypermethrin netting intervention and total ${ }^{\#}$ is the total number of sand flies caught and dead after $24 \mathrm{~h}$ in all chicken sheds and on all nights after the l-cyhalothrin spray intervention. = mean number of $L u$. longipalpis collected on each night; \pm sem $= \pm$ standard error of the mean. 
Table 4. Longitudinal trapping experiment: numbers of male and female Lu. longipalpis trapped in a pheromone baited modified HP trap in real chicken sheds treated with either a-cypermethrin impregnated netting or I-cyhalothrin residual spray. 


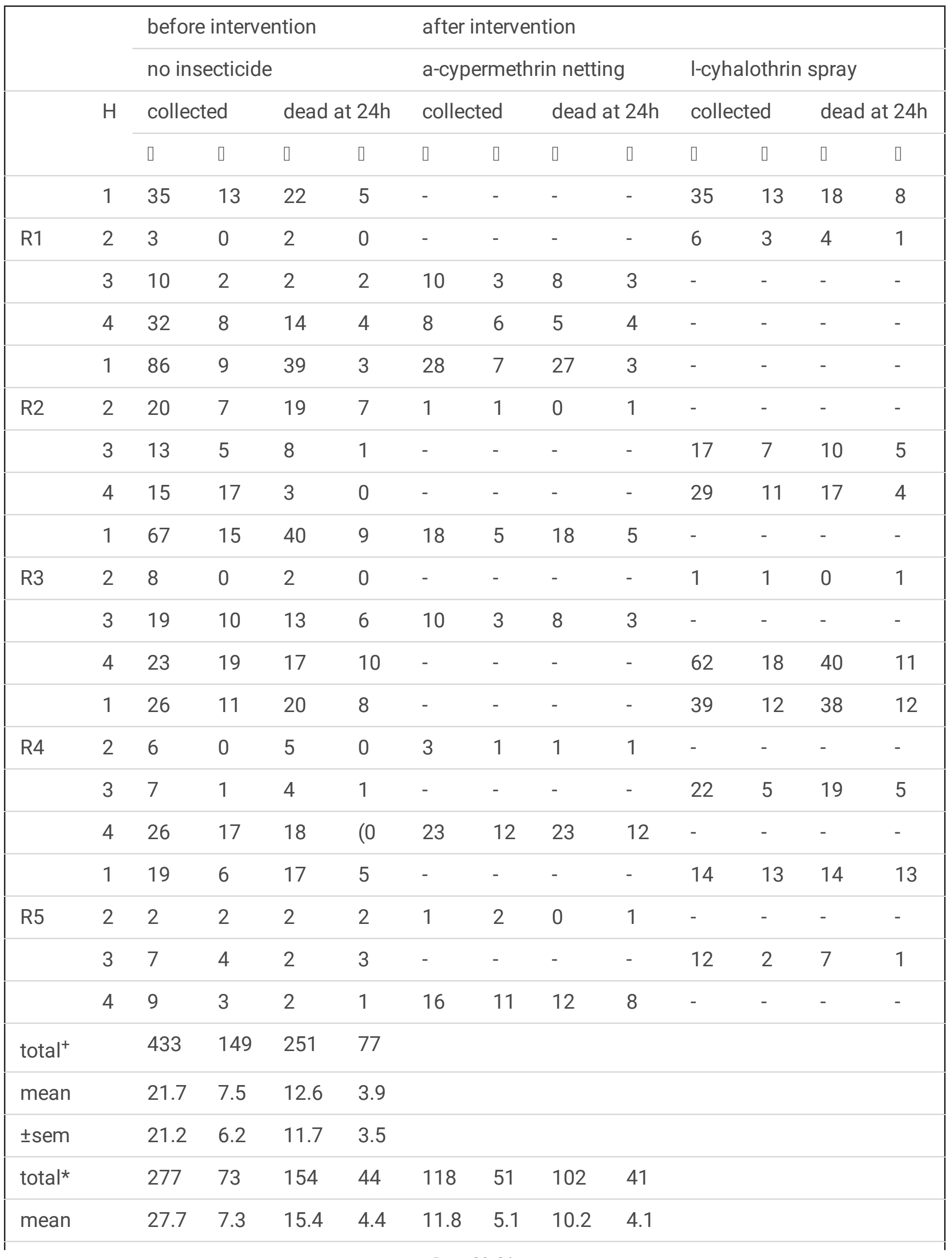




\begin{tabular}{|lccccccccccc|} 
\pm sem & 8.8 & 1.8 & 4.5 & 1.1 & 2.9 & 1.2 & 3.1 & 1.1 & & & \\
total $^{\#}$ & 156 & 76 & 97 & 33 & & & & 237 & 85 & 167 & 61 \\
\hline mean & 15.6 & 7.6 & 9.7 & 3.3 & & & 23.7 & 8.5 & 16.7 & 6.1 \\
\pm sem & 3.2 & 2.2 & 2.6 & 1.1 & & & 5.7 & 1.8 & 4.2 & 1.5 \\
\hline
\end{tabular}

$\mathrm{R}=$ experimental replicate; $\mathrm{H}=$ house in which the chicken shed was located; before intervention=number of male and female Lu. longipalpis collected when no insecticide treatment was present ( $1^{\text {st }}$ night); after intervention=number of male and female $L u$. longipalpis collected when either a-cypermethrin netting or $1-$ cyhalothrin spray insecticide treatment was present in the chicken shed $\left(2^{\text {nd }}\right.$ night). Total ${ }^{+}$is the total number of sand flies collected and dead after $24 \mathrm{~h}$ in all chicken sheds and on all nights prior to intervention. Total* is the total number of sand flies collected and dead after $24 \mathrm{~h}$ in all chicken sheds and on all nights after the a-cypermethrin netting intervention and total ${ }^{\#}$ is the total number of sand flies collected and dead after $24 \mathrm{~h}$ in all chicken sheds and on all nights after the I-cyhalothrin spray intervention.

Table 5. Control trap catches. Numbers of male and female Lu. longipalpis collected in HP suction traps (with light bulb) at 2 houses without insecticide treatment. 


\begin{tabular}{|c|c|c|c|c|c|c|c|c|}
\hline \multirow{3}{*}{$\begin{array}{l}\text { collection } \\
\text { date }\end{array}$} & \multicolumn{4}{|c|}{ House A } & \multicolumn{4}{|c|}{ House B } \\
\hline & \multicolumn{2}{|c|}{ collected } & \multicolumn{2}{|c|}{ dead at $24 \mathrm{~h}$} & \multicolumn{2}{|c|}{ collected } & \multicolumn{2}{|c|}{ dead at $24 \mathrm{~h}$} \\
\hline & Q & प & Q & प & Q & प & Q & प \\
\hline $26 / 01$ & 13 & 9 & 0 & 0 & 12 & 4 & 2 & 0 \\
\hline $27 / 01$ & 8 & 6 & 3 & 2 & 6 & 7 & 2 & 2 \\
\hline 28/01 & 4 & 1 & 0 & 0 & 4 & 7 & 3 & 7 \\
\hline 29/01 & 4 & 1 & 3 & 0 & 4 & 0 & 0 & 0 \\
\hline \multirow[t]{2}{*}{ Total } & 29 & 17 & 6 & 2 & 26 & 18 & 7 & 9 \\
\hline & 7.3 & 4.3 & 1.5 & 0.5 & 6.5 & 4.5 & 1.8 & 2.3 \\
\hline \pm sem & 2.1 & 2.0 & 0.9 & 0.5 & 1.9 & 1.7 & 0.6 & 1.7 \\
\hline $12 / 05$ & 33 & 16 & 13 & 9 & 6 & 0 & 0 & 0 \\
\hline $13 / 05$ & 26 & 14 & 6 & 11 & 2 & 1 & 1 & 1 \\
\hline $14 / 05$ & 14 & 14 & 4 & 0 & 15 & 4 & 8 & 2 \\
\hline $15 / 05$ & 17 & 4 & 4 & 0 & 2 & 4 & 0 & 0 \\
\hline \multirow[t]{2}{*}{ Total } & 90 & 48 & 27 & 20 & 25 & 9 & 9 & 3 \\
\hline & 22.5 & 12 & 6.8 & 5 & 6.3 & 2.3 & 2.3 & 0.8 \\
\hline \pm sem & 4.3 & 2.7 & 2.1 & 2.9 & 3.1 & 1.0 & 1.9 & 0.5 \\
\hline 07/07 & 34 & 12 & 8 & 3 & 5 & 0 & 1 & 0 \\
\hline 08/07 & 1 & 12 & 1 & 3 & 2 & 2 & 0 & 0 \\
\hline 09/07 & 13 & 6 & 3 & 2 & 2 & 4 & 0 & 1 \\
\hline $10 / 07$ & 5 & 1 & 4 & 1 & 1 & 1 & 1 & 1 \\
\hline \multirow[t]{2}{*}{ Total } & 53 & 31 & 16 & 9 & 10 & 7 & 2 & 2 \\
\hline & 13 & 7.8 & 4.0 & 2.3 & 2.5 & 1.8 & 0.5 & 0.5 \\
\hline \pm sem & 7.3 & 2.7 & 1.5 & 0.5 & 0.9 & 0.9 & 0.3 & 0.3 \\
\hline $13 / 09$ & 4 & 2 & 2 & 1 & 3 & 1 & 1 & 0 \\
\hline $14 / 09$ & 2 & 2 & 0 & 0 & 8 & 3 & 0 & 0 \\
\hline $15 / 09$ & 2 & 0 & 1 & 0 & 4 & 4 & 1 & 1 \\
\hline $16 / 09$ & 1 & 1 & 0 & 0 & 9 & 5 & 2 & 0 \\
\hline Total & 9 & 5 & 3 & 1 & 24 & 13 & 4 & 1 \\
\hline
\end{tabular}




\begin{tabular}{|lllllllll|} 
& 2.3 & 1.3 & 0.8 & 0.3 & 6.0 & 3.3 & 1.0 & 0.3 \\
\pm sem & 0.6 & 0.5 & 0.5 & 0.3 & 1.5 & 0.9 & 0.4 & 0.3 \\
\hline
\end{tabular}

Collection date $=$ the date on which the sand flies were collected; House $(\mathrm{A}$ or $\mathrm{B})=$ the house in which the

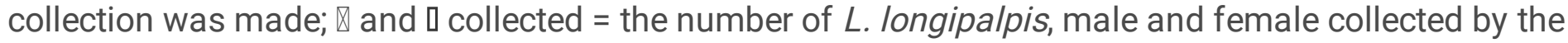

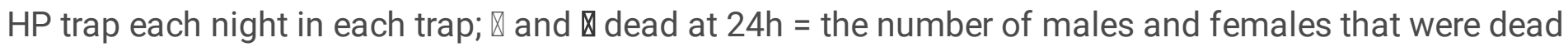

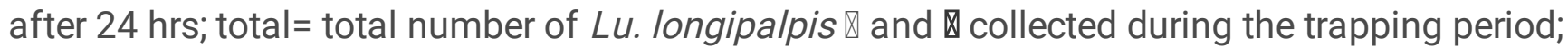
$=$ mean number of $L u$. longipalpis collected on each night; \pm sem $= \pm$ standard error of the mean.

\section{Figures}




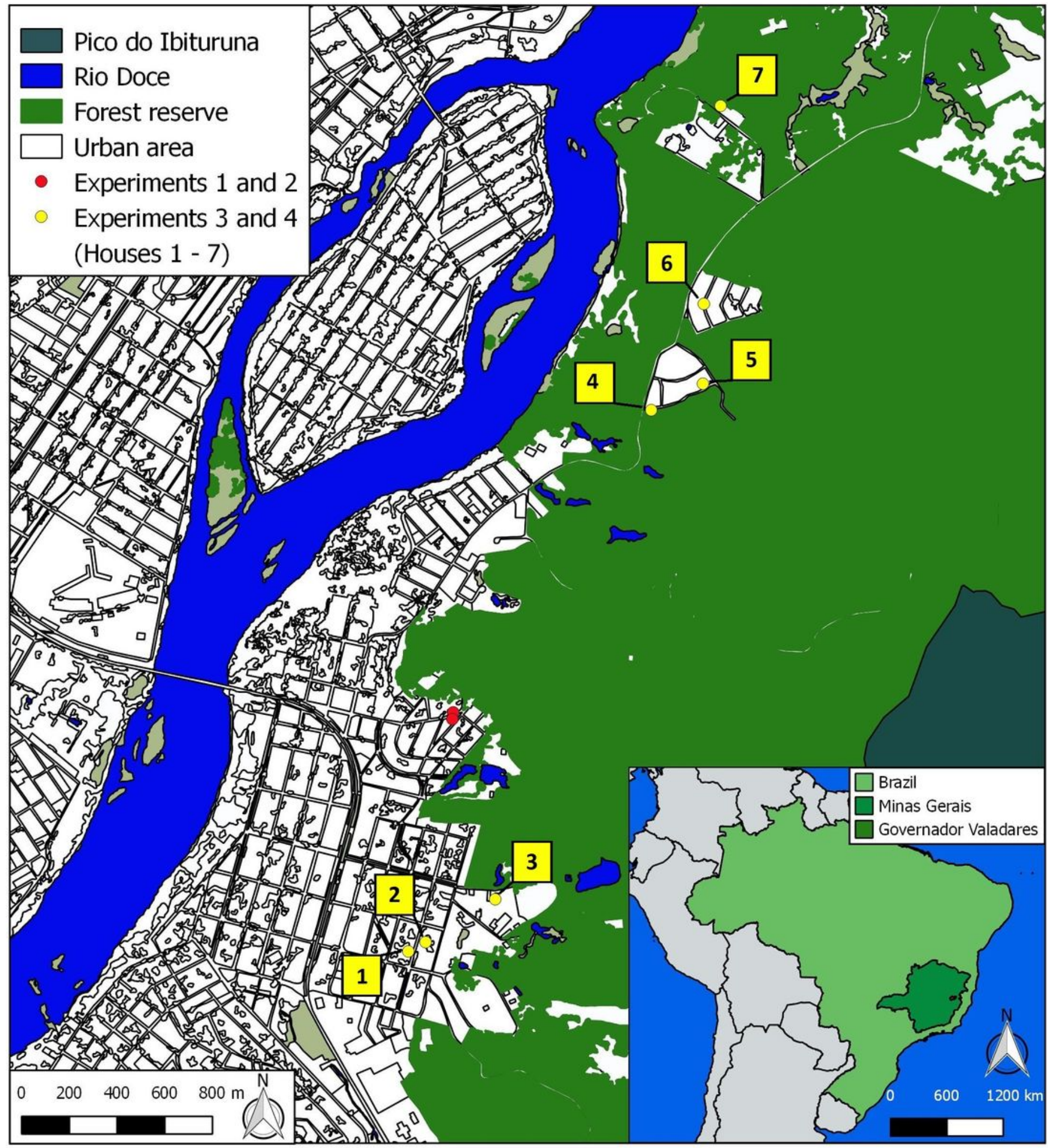

Figure 1

The locations for experiments 1 and 2 (red circles) and experiments 3 and 4 (yellow circles) are shown. The map was built using the Geographic information system QGIS 2.16. Cartographic bases were obtained from the Instituto Brasileiro de Geografia e Estatistica (IBGE) and Agência Nacional de Águas (ANA). Coordinates were assigned using The Universal Transverse Mercator (UTM) and the reference system SIRGAS 2000, zona 24S. 

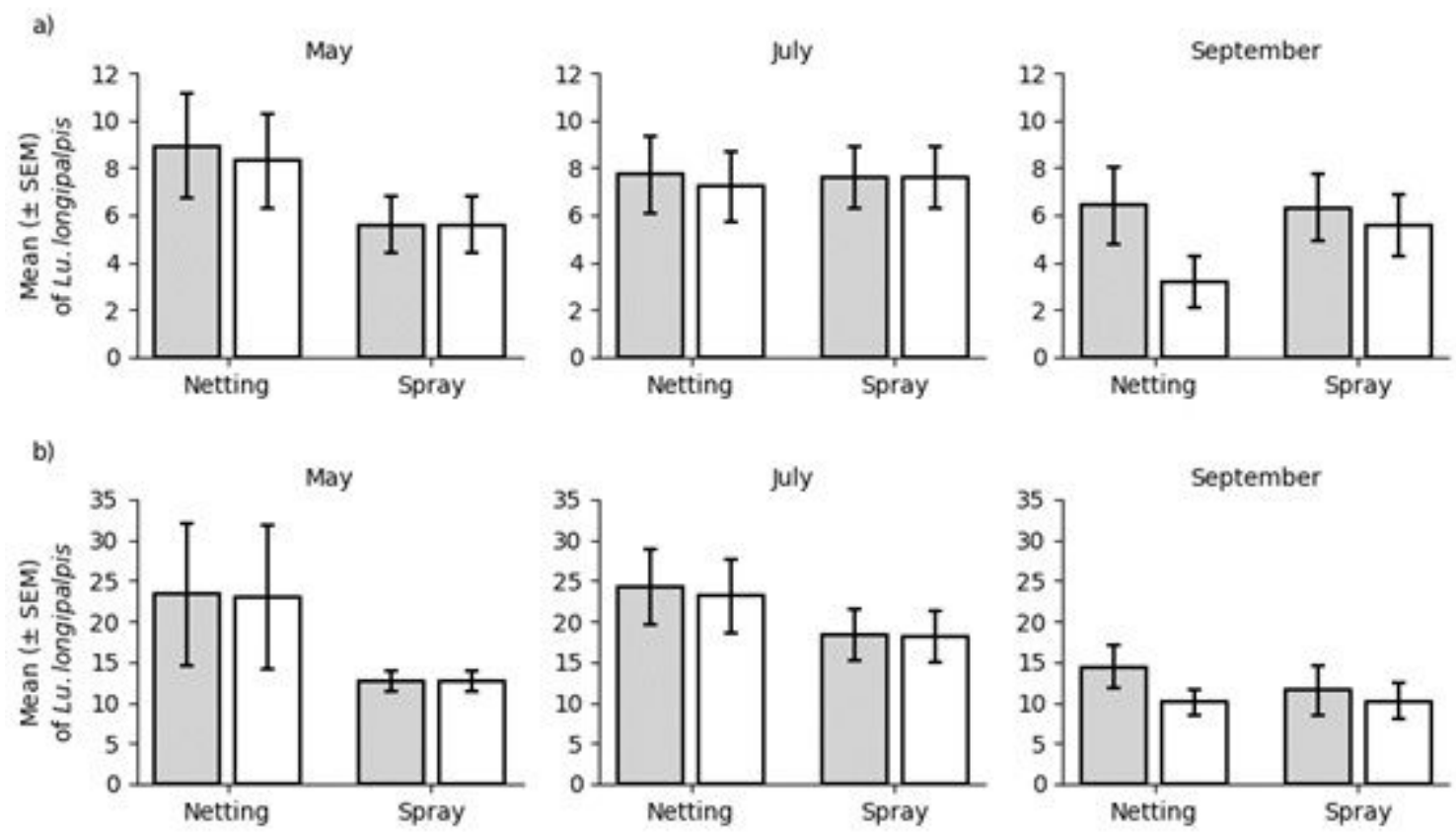

Figure 2

a) females and b) males, captured (grey bars) and dead after 24 hrs (white bars) during the trapping

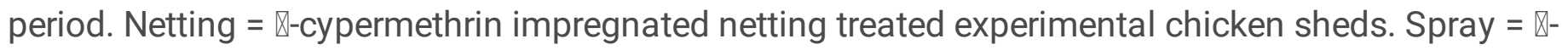
cyhalothrin residual spray treated experimental chicken sheds. Values shown are the mean number of females or males caught per day during the experiment \pm standard error of the mean.

\section{Supplementary Files}

This is a list of supplementary files associated with this preprint. Click to download.

- Additionalfile1.docx

- Additionalfile2.docx

- Graphicalabstract.jpeg 